\title{
DEMOCRACIA, PODER E EDUCAÇÃO POPULAR: REFLEXÕES A PARTIR DE PAULO FREIRE
}

\author{
Jaime José Zitkoski ${ }^{1}$ \\ Marion Machado Cunha ${ }^{2}$
}

\begin{abstract}
Resumo: No atual contexto político mundial, muitos câmbios sócio-políticos estão em curso, além de tantos outros que poderãosuceder-se. A crise da democracia representativa, o retorno de posições conservadoras que defendem a volta da ditadura, o pragmatismo que apenas vê o interesse particular, entre tantos outros riscos às conquistas da frágil democracia brasileira. Nesse âmbito prático do campo políticodespontam novos desafios à sociedade civil organizada. Um deles é o debate sobre a reinvenção do poder, desde os múltiplos espaços sociais, até as instâncias institucionalizadas do Estado hoje vigente, para alavancar novas conquistas da vida republicana e não admitir retrocessos. Freire nos inspira a debater a radicalidade da democracia e sua efetiva construção a partir da cultura cidadã, que requer a esperança no futuro e a luta por uma sociedade livre e justa como horizonte de um novo projeto societal.
\end{abstract}

Palavras-Chave: Democracia; Reinvenção do Poder; Educação Popular; Freire

1 Doutor em Educação. Professor da FACED/UFRGS. 00086365@ufrgs.br.

2 Doutor em Educação. Professor da UNEMAT. marioncunha@yahoo.com.br. 


\section{INTRODUÇÃO}

Um dos maiores desafios práticos na atualidade política é a reinvenção da democracia moderna em seu modelo de democracia representativa. A complexidade dos sistemas sociais constituídos e a crise de alternativas para grande parte da população, principalmente nos aglomerados urbanos, produz cada vez maior distância entre a classe política e a sociedade civil. Esse fator está causando um verdadeiro ciclo vicioso nas sociedades contemporâneas a partir do qual se efetivam os interesses de uma minoria que, apropriando-se dos aparelhos políticos, por meio das estratégias do poder econômico e da mídia, governam a sociedade, segundo seus planos de manutenção e ampliação do poder econômico e político para o futuro. A consequência direta desse fenômeno é a atual dependência e/ou atrelamento dos Estados Nacionais ao mercado econômico globalizado que dita as regras para as políticas nacionais e passa a definir os destinos de milhões de seres humanos segundo os critérios do lucro e da garantia de concentração das riquezas. As dimensões dessa riqueza se conjugam com o esvaziamento das condições de dignidade da produção da vida de grande parte da parcela da população, nacional e mundialmente. Aumenta a população global despossuída e empobrecida sendo forjada nos países periféricos.

Os países periféricos encontram-se em uma situação dramática, pois estão sendo sufocados pelos países ricos em suas estratégias de controle mundial em função dos mecanismos da globalização econômica, principalmente pelo setor financeiro (da lógica dos serviços da dívida e alta remuneração do capital especulativo), alinhada às regras do projeto político neoliberal. Para os países periféricos propõe-se um desmonte do Estado com a finalidade de exaurir sua capacidade de políticas sociais e de ações públicas que possam se viabilizar em sujeitos coletivos de nova força social.

Ainda se soma a forte concorrência mundial intercapitalista que está produzindo a falência das economias nacionais. Valendo-se dos mecanismos da livre concorrência mundial, o capital nacional não consegue competir com as potências econômicas materializadas em grandes multinacionais e megafusões das empresas com sedes nos países de primeiro mundo. As privatizações realizadas por intermédio das políticas liberalizantes produzem uma verdadeira transferência do patrimônio nacional para o capital internacionalizado. Todos esses aspectos surgem como consequências de um projeto político social previamente definido pelos países ricos com o objetivo de reaquecer suas economias e controlar as nações periféricas via sutilezas das regras do livre 
mercado em nível global. E, para nós latino-americanos, esse fenômeno da globalização econômica está produzindo um quadro social desesperador, que ameaça inviabilizar econômica, social e politicamente as nações do continente. A retórica neoliberal que nos concebe como países emergentes (por estarmos em ascensão para o nível do "Primeiro Mundo"- desenvolvido e civilizado) deve ser lida e interpretada pelo avesso, pois a realidade nos mostra que há uma crescente exclusão social, de barreiras materializadas aos bens sociais e coletivos, com o aumento da marginalidade, violência e desintegração do tecido da sociedade. Todos esses aspectos constituem um verdadeiro caos social que compromete, inclusive, a legitimidade política do Estado em questão.

Nesse cenário, que interesses representam os governos democraticamente eleitos pelo voto, mas que, definem seus planos a partir do comportamento do livre mercado? Quem de fato está governando no atual contexto da globalização da economia e do modelo político controlado pelo mercado no mundo? Para além da democracia representativa, o que pode garantir no futuro maior autonomia dos povos e verdadeira representatividade dos interesses sociais no conjunto das sociedades contemporâneas, que são complexas e apresentam alta densidade populacional?

\section{A CRISE DA DEMOCRACIA REPRESENTATIVA: SEUS LIMITES E ALTERNATIVAS}

As eleições no Brasil, previstas legalmente para acontecerem a cada quatro anos, a partir de regras previamente definidas à luz de nossa constituição, que reforça prioritariamente a democracia representativa, apenas legitimam as normas instituídas que garantem os interesses da parte já incluída da sociedade. Com a forte exclusão social que marginaliza milhões de cidadãos das decisões importantes da vida social e com as estratégias de manipulação da opinião pública via poder da mídia, somada ao alto grau de corrupção política existente em nosso meio, as decisões políticas, mesmo que, em conformidade com a legislação vigente, tornam-se cada vez mais distantes, pois não representam a vontade da maioria ao reproduzirem simplesmente os interesses partidários hegemônicos, que controlam os espaços políticos institucionalizados. Esse é um dos fatores que aprofundam a atual crise brasileira. A participação política do cidadão cinde-se da vontade de alternativas da maioria das pessoas que já vivenciam as precariedades de uma sociedade concentradora e desigual. Contudo, não consiste apenas num cenário nacional, há relações necessárias 
com ações mundiais dos poderes dos países capitalistas centrais.

A crise mundialmente produzida, para os países periféricos implicam em várias ações articuladas. Uma articulação consiste na associação dos países centros do capital (na atualidade, os estadunidenses, e o conjunto da União Europeia, comandada prioritariamente pela Alemanha) que atuam com os seus capitais financeiros, suas agências financeiras e intergovernamentais, no desmantelamento das economias nacionais emergentes. E, ainda, de forma combinada, a reorganização da força hegemônica dos EUA depois da crise de 2008, da "bolha imobiliária" norte-americana. A aguda crise de mercado mundial levou ao que Fiori chama de "novo estatuto imperial":

O novo estatuto imperial dos EUA, somado a sua política interna de austeridade fiscal - induzida pela crise financeira de 2008 - os levaram a adotar uma nova forma de administração do seu poder global, cada vez mais arbitral e "terceirizada", por meio da promoção ativa de divisões e "equilíbrios de poder" regionais[...]. (FIORI, 2013, p.34)

No movimento global do capital sobre os países periféricos com as associações nacionais, de caráter conservadora e dependente, não refere somente ao controle econômico dos países periféricos, mas do estatuto imperial de domínio político globalizado, de "forma arbitral e terceirizada",como mecanismo de antever qualquer ameaça ao projeto hegemônico dos países denominados de ricos. O exemplo disso consiste no desmonte do BRICS (Brasil, Rússia, Índia, China e África do Sul). O BRICS, enquanto reconfiguração estratégica de poder econômico e de reposicionamento da política mundial pela cooperação de países emergentes, "em 2010, o PIB conjunto dos cinco países [...] havia alcançado já 19 trilhões de dólares, ou seja, 25\% do PIB mundial" (FIORI, 2013, p. 47). O BRICS, em síntese, atua como uma alternativa econômico-financeira à tutela dos países ricos.

Há uma luta travada entre os centros capitalistas, a hegemonia americana e os países periféricos. E, disso, a luta a ser travada nos países periféricos está centrada sob dois pilares: o papel do Estado e a Democracia. E é, sob esse cenário, que a democracia brasileira apresenta-se assaltada pela classe política que representa a materialidade da terceirização e arbitral norte-americana de um lado e, a manutenção dos privilégios dessa (antiga) associação política de elite brasileira em sua tradição "arcaica" (FERNANDES, 2006) com os centros capitalistas.

É por tais razões que, enquanto alternativa de transformação social, necessitamos hoje, de modo estratégico, a recriar a democracia superando os 
atuais modelos políticos, que constituem a democracia representativa. Portanto, não basta apenas conquistar o poder já instituído por vias democráticas, mas impõe-se a necessidade de alçar a política a outros níveis de controle social público que superem o atual círculo da democracia representativa, reinventando outras formas de fazer política, que não estão contempladas pelo sistema democrático vigente.

Para superar os aspectos meramente formais da democracia ocidental (que apenas confere direitos legais dos cidadãos pertencentes a determinada organização social, mas exclui grande parcela da população do acesso àquilo que é de Direito), faz-se necessária a organização da sociedade civil em níveis condizentes com as atuais exigências de reestruturação do Estado e da política contemporânea, através do controle público dos mesmos (FREIRE, 2000).

Diante desses desafios, à organização popular, principalmente os Movimentos Sociais que lutam por mais democracia e pela distribuição justa do poder e das riquezas produzidas socialmente, se impõe a tarefa de servir como instância de reinvenção da democracia. Precisamos no Brasil avançar na organização da sociedade civil, equilibrando o poder dos poderes já instituídos com novas formas de poder popular, na direção de romper com os vícios do assistencialismo, acomodação e indiferença e promover, gradativamente, uma intensa mobilização da sociedade diante dos problemas sociais mais dramáticos, tais como: desemprego, exclusão social, violência, marginalidade, massificação cultural, entre outros. Essa mobilização da sociedade através de novas formas de construir a democracia é possível se partirmos da realidade prática em que o povo vive no seu cotidiano e despertarmos o interesse da população afetada por determinados problemas, ou desafios mais diretamente voltados ao seu cotidiano.

É nessa direção que a democracia representativa poderá ser complementada por um sistema misto entre ela própria e a democracia direta, para as quais a sociedade civil tenha mecanismos de controlar o Estado (DEMO, 1993). A riqueza e qualificação da esfera política de uma sociedade está em seu grau de politização que se materializa na participação ativa dos cidadãos nas decisões e atividades públicas. É a sociedade civil, constituída por cada cidadão (enquanto sujeito social), quem deve decidir os rumos de sua história e não apenas escolher representantes que seriam os iluminados para decidir o futuro de todos.

A reinvenção do poder passa pela reinvenção da política, principalmente do modelo de democracia representativa hoje vigente. Como bem diz Paulo 
Freire (1994), precisamos uma pedagogia da política que articule a luta e a esperança, o sonho com o embate. Esse processo requer uma posição radical de desconstrução do que está envelhecido e de modo ultrapassado, conserva as antigas relações de poder via assistencialismo, troca de favores e conluios entre lideranças. Mas, para além da desconstrução, é necessário construir um novo projeto, criando alternativas para que seja possível superar o histórico colonialismo aqui implantado e trilharmos nossos próprios caminhos a partir de um projeto autêntico e verdadeiramente cidadão - porque construído com a participação de todos os sujeitos históricos discutindo seus próprios problemas e interferindo na realidade rumo à transformação social.

Estamos em um momento histórico, cuja tarefa central é a construção de uma DEMOCRACIA RADICAL, na qual todos nos sintamos representados, e que compatibilizem Igualdade e Liberdade, Unidade e Multiplicidade, Diversidade e Diferença, Direitos das Maiorias e Direitos das Minorias. (MEJÍA, 1994, p.73)

Esse processo de superação do atual estágio da democracia representativa requer caminhos de comunicação social que sirvam de alternativa ao grande poder da mídia, que está intimamente sintonizado com o controle do poder político pelas classes dominantes. O empoderamento dos oprimidos (MEJIA, 1994), enquanto resistência frente aos meios de comunicação de massa que alienam e homogeneízam as consciências, só será possível através de novas estratégias de comunicação popular que deem reais condições de reflexão crítica e consciente às pessoas no seu cotidiano social. Portanto, a mobilização social rumo à transformação da política e das estruturas sociais requer o diálogo, o debate e a permanente comunicação popular entre os que mais sofrem o atual ciclo de opressão social.

\section{A REINVENÇÃO DA DEMOCRACIA E DA PARTICIPAÇÃO POPULAR: UMA UTOPIA POSSÍVEL?}

A utopia política de libertação dos oprimidos é o ponto de partida, segundo Freire, para fundamentar um novo projeto de sociedade enquanto superação da atual realidade sociocultural. Ou seja, os oprimidos não têm compromisso político com o sistema vigente que os oprime e, dessa forma, quanto mais clareza política vão conquistando do processo histórico-dialético em que vivem, mais fortemente defenderão a utopia de uma nova sociedade a ser construída 
desde o embate prático da necessária reinvenção da democracia.

Para além da desumanização que sofrem diariamente em sua própria pele, (a exemplo das condições sociais humilhantes que machucam seus corpos conscientes, envelhecendo-os mais cedo, impondo-lhes carências nas necessidades básicas, ou limitando-os a uma vida marcada pela dor e violência) os oprimidos, no íntimo de seu ser, aspiram a novos modos de existência humana. A realidade socialmente construída, que os limita e atrofia enquanto ser mais, jamais significará o horizonte possível da existência de milhões de seres humanos em todo mundo.

Diante dessa realidade em que ainda vivem milhões de pessoas hoje no Brasil, por mais ingênua que seja a percepção (visão de mundo) de um ser humano, há a tomada de consciência das mesmas de que a sua condição social é de opressão e desumanização. Esse fato concreto na história humana é o impulso fundante da utopia em uma nova sociedade mais humana e digna para todos. Eis o desafio histórico da luta política dos oprimidos que se impõe enquanto concretização da utopia de um projeto de sociedade sem opressores e sem oprimidos.

Como distorção do ser mais, o ser humano leva os oprimidos, cedo ou tarde, a lutar contra quem os fez menos. E esta luta somente tem sentido quando os oprimidos, ao buscarem recuperar sua humanidade, que é uma forma de criá-la, não se sentem idealistamente opressores, nem se tornem de fato, opressores dos opressores, mas restauradores da humanidade de ambos. Eis aí a grande tarefa humanista e histórica dos oprimidos - libertar-se a si e aos opressores. (FREIRE, 1993, p.30)

Mas, quais são as bases concretas para a realização histórica a utopia político-social de libertação/emancipação dos oprimidos? É algo que pode ser concretizado na história ou é apenas um sonho idealista de visionários descolados da realidade? E se é realizável historicamente, por que ainda não foi concretizada pelas classes populares na América Latina, que há décadas começaram a se articular nessa direção? São questões desafiadoras, tanto quanto é o desafio da própria utopia dos oprimidos efetivarem sua autêntica história, enquanto sujeitos da transformação do mundo. Entretanto, uma leitura mais atenta de Freire nos remete para o esclarecimento da complexidade em que hoje vivemos.

Um primeiro argumento que Freire nos oferece sobre a possibilidade concreta de realização dessa utopia política de reinvenção da democracia a partir da luta dos oprimidos e dos que se solidarizam verdadeiramente com 
eles, é que o ser humano é o ser da práxis, da luta e da ação no mundo. Ou seja, a intervenção no mundo é o modo essencialmente humano de existir e, por essa razão, o mundo jamais estará em plena elaboração de si mesmo. Portanto, as realidades sociais, culturais e políticas constitutivas de nosso mundo histórico são construções humanas que sempre estarão passíveis de sofrerem transformações, tanto em níveis lentos e gradativos, quanto em níveis de rupturas mais profundas na estrutura fundante, que produzem transformações radicais nas mesmas.

Outro argumento forte que Freire tem defendido, desde suas primeiras obras, sustenta a tese de que somente os oprimidos representam a utopia e a esperança da libertação humana na história.

Este ensinamento e este aprendizado têm de partir, porém, dos 'condenados da terra', dos oprimidos, dos esfarrapados do mundo e dos que com eles realmente se solidarizam [...]. Quem, melhor que os oprimidos, se encontrará preparado para entender o significado terrível de uma sociedade opressora? Quem sentirá, melhor que eles os efeitos da opressão? Quem, mais que eles, para ir compreendendo a necessidade de libertação. (Idem, p.31)

A justificativa dessa argumentação acima se encontra na análise das contradições existenciais em que os oprimidos vivem, sofrendo no cotidiano a opressão concreta de seu ser que os desumaniza, a própria realidade faz com que eles aspirem a uma vida mais digna, livre e de realização de seu ser mais. Tais contradições impulsionam a tomada de consciência (mesmo que ainda de modo ingênuo) dos oprimidos das reais condições de opressão em que vivem. Mas, como já assinalamos no item anterior, a tomada de consciência não basta, e esse primeiro nível de consciência das contradições deve aprofundar-se em níveis problematizadores da realidade rumo à práxis transformadora das estruturas sociais que os oprimem. Freire é bem claro em sua análise política ao defender a necessária emersão da consciência do oprimido - que implica a superação de si mesmo enquanto hospedeiro da opressão, por alimentar o medo da liberdade que o leva a acomodar-se ou conformar-se com a realidade para que o processo utópico-libertador se torne efetivamente possível. Contudo, tal processo de construção da pedagogia libertadora não ocorre espontaneamente, mas exige um trabalho intencional (planejado) de criticização da consciência a partir do constante desafio que tenciona açãoreflexão-nova ação.

Esse é o papel de uma pedagogia libertadora/emancipatória - a pedagogia do oprimido - que deve ser desencadeada por autênticos líderes (que surgem 
do povo e com ele se comprometem) enquanto verdadeiros pedagogos junto com as classes populares. A elaboração dessa pedagogia deve ser impulsionada pelo constante processo dialógico-crítico-participativo e esperançoso para que todos possam compreender as razões dos fatos que constituem a realidade e, assim, se engajar, de forma consciente, na luta de transformação da realidade que implica estratégias e táticas concretas de intervenção no mundo historicamente construído. Nesses termos, Freire defende que a pedagogia do oprimido é uma obra coletiva, solidária e exige a humildade dos líderes políticos. Enquanto processo político, essa obra

tem de ser forjada com ele e não para ele, enquanto homens ou povos, na luta incessante de recuperação de sua humanidade. Pedagogia que faça da opressão e de suas causas o objeto da reflexão dos oprimidos, de que resultará o seu engajamento necessário na luta por sua libertação, em que esta pedagogia se fará e refará. (Idem, p.32)

Então, a construção dessa pedagogia libertadora a partir dos próprios oprimidos implica conceber uma obra sempre incompleta, aberta ao futuro, que se reelaborará no processo intersubjetivo e dialógico de sua própria elaboração. Esse é um terceiro argumento defendido por Freire sobre a possibilidade e condição histórica da utopia política de libertação. Freire entende, nesse sentido, que a intervenção prática no mundo como busca de transformação do mesmo não pode ser entendida como uma ação de indivíduos apenas, mas da práxis coletiva, solidária, dialógica e problematizadora da realidade. Por isso, de temporalidade transformadora, porque o "homem existe $[\ldots]$ no tempo. Está dentro. Está fora. Herda. Incorpora. Modifica” (FREIRE, 1967, p. 41).

Se o ser humano é o ser da práxis, a exigência histórica da utopia de libertação dos oprimidos requer um novo sentido para a práxis humana. $\mathrm{O}$ sentido da práxis libertadora emerge da convivência intersubjetiva a partir da qual os oprimidos vão se tornando capazes de descobrir novos sentidos de sua existência no mundo e, igualmente, elaborar novas visões de mundo que anteriormente não lhes eram possíveis. Nesse sentido, o debate crítico, que é oportunizado a partir do encontro dialógico entre os sujeitos sociais, é capaz de desencadear um poder político muitas vezes subestimado por nós. O poder que brota do processo de resinificar o mundo através da comunhão intersubjetiva e da valorização ser pessoa. Algumas passagens que Freire relata em sua obra Pedagogia do Oprimido são bastante expressivas dessa realidade:

Escutamos, certa vez, um líder camponês dizer, em reunião, numa das unidades 
de produção da experiência chilena de reforma agrária: 'Diziam de nós que não produzíamos porque éramos borrachos, preguiçosos. Tudo mentira. Agora, que estamos sendo respeitados como homens, vamos mostrar a todos que nunca fomos borrachos, nem preguiçosos. Éramos explorados, isto sim. (p.51)

Em outra passagem no livro Aprendendo com a própria história em coautoria com Sérgio Guimarães, Freire expressa a importância do diálogo para a transformação política da sociedade, principalmente para a substantividade prática da democracia vivenciada em sociedade. Falando sobre Herbert de Souza (o Betinho) - de sua coragem na luta política de resistência à ditadura militar que sofremos no período recente de história brasileira - Freire destaca o valor do diálogo e da vivência intersubjetiva para a política.

Me lembro de que uma vez fui dar um curso em Toronto onde ele (Betinho) vivia. Guiando o seu carro pelas ruas da cidade, me disse: "Paulo, hoje no Brasil um grupo de mulheres que se unam para bordar ou fazer renda pode ter uma importância revolucionária enorme". Veja, é isso que eu considero ser a sensibilidade política de um bom político, aquele que descobre, que convive com a história, ao invés de apenas ser atravessado por ela. (p. 32-33)

O empoderamento dos oprimidos, que brota das vivências de união, solidariedade, debate, diálogo problematizador da realidade e das trocas a partir das relações intersubjetivas e do encontro entre as pessoas, é a grande esperança de que o futuro pode ser diferente e, portanto, será possível construir um mundo mais belo e humanizado.

As trocas solidárias vivenciadas desde as experiências simples do cotidiano, que brotam da vida partilhada dos oprimidos, constituem uma força política de real importância, capaz de impulsionar ações práticas de uma intervenção no mundo mais organizada a partir da qual o processo de libertação toma corpo na história e torna-se algo concreto, palpável e dinâmico diante dos desafios da realidade. Uma das expressões mais efetivas na realidade social dessa dialética, que tenciona o presente com o futuro, são os Movimentos Sociais organizados em toda a América Latina (e também em outras partes do mundo), que traduzem, na prática, a luta das classes populares rumo à construção de uma nova sociedade.

Os Movimentos Sociais são uma prova concreta de que a Pedagogia dos Oprimidos já está sendo elaborada e não é mera utopia de visionários ou intelectuais abstraídos da realidade. É óbvio que todo o processo histórico dialeticamente construído implica avanços e recuos, assim como as estratégias de organização política das classes sociais que se antagonizam no processo de 
luta política encontram-se em permanente disputa de poder. Dessa forma, a Pedagogia do Oprimido, que tem origem histórica, também sofre reelaborações modificando historicamente suas táticas de luta contra-hegemônica diante do sistema do capital, hoje mundialmente dominante.

Mas, a luta concreta desencadeada pelos Movimentos Sociais Populares organizados, coerentes com os autênticos interesses políticos das classes populares, são exemplos concretos de que o processo de conscientização é possível, a organização dos oprimidos (classes populares) produz novos desafios de lutas futuras.

Nesse sentido, a articulação de Movimentos Sociais Populares em âmbito maior, de nível regional ou nacional, demonstra a potencialidade do poder democrático que emerge da vivência solidária e dialógica entre os mais oprimidos, humilhados e excluídos do atual sistema político em curso. No Brasil, o MST é um Movimento exemplar desse empoderamento dos oprimidos quando lutam com esperança, diálogo e utopia política. Em outros países da América Latina temos outros inúmeros exemplos que expressam a realidade política de resistência dos oprimidos tais como O Chiapas no México, os movimentos de Libertação Nacional (Colômbia), o Movimento Revolucionário no Peru, entre outros.

Diante das análises sobre as experiências históricas já registradas em longas décadas de elaboração de uma Pedagogia da Luta Política dos oprimidos, Freire reafirma a necessária vigilância contra os sectarismos sempre tentadores para a justificação de práticas opressoras. A verdadeira postura dos oprimidos que lutam pela libertação de si próprios e dos opressores, e dos que se solidarizam nessa luta, deve ser a postura política radical que implica a vivência democrática e o testemunho coerente da utopia de sociedade por que lutamos. Nesse sentido, o alerta de Freire para não sectarizarmos a nossa visão de mundo, bem como nossas práticas socioculturais e políticas enquanto sujeitos da luta pela transformação do mundo, constitui uma contribuição original e cada vez mais atual para a reflexão política diante dos desafios da utopia de uma nova sociedade em um mundo pseudodemocrático e sectarizado a exemplo das sociedades contemporâneas governadas pela mídia que massifica a cultura e pelo mercado financeiro que escraviza e explora cada vez mais os povos já dominados e empobrecidos.

A postura radicalmente democrática requer, acima de tudo, a superação política do status de democracia formal que, na maioria dos países que a seguem, apenas assegura direitos na lei, sem garantir a concretude desses 
direitos a grande parte de seus cidadãos. Portanto, a luta política dos oprimidos deve ser radicalmente solidária com todos os segmentos e, para que as diferentes lutas de cada setor da sociedade se converta em uma articulação de um movimento comum a todos rumo à transformação da sociedade, faz-se necessária uma leitura dialética (crítica e problematizadora da realidade) dos diferentes momentos do embate prático que incide contra as estruturas sociais opressoras.

Não há garantia, segundo a visão profundamente dialética e dialógica de Freire, de que, uma vez as classes populares conquistando o poder político, consigam manter, no futuro, o controle desse poder. A luta política não pode ser concebida de modo linear porque, se assim for, as práticas políticas se tornam sectárias e a utopia já não terá mais espaço para florescer e tornar-se, efetivamente, uma alternativa à política opressora. Diante do permanente jogo de forças do processo político historicamente inaugurado - que produz o embate prático entre elite e classes populares, manutenção dos interesses das classes dominantes, ou democratização do acesso prático aos direitos de todos surgirão sempre novos contextos que exigirão novos embates dialetizadores da própria vida em sociedade.

Em outras palavras, o que está em jogo é a permanente luta de classes que jamais se exauriu na história humana até hoje vivenciada.

O que acontece é que a luta é uma categoria histórica e social. Tem, portanto, historicidade. Muda de tempo-espaço. A luta não nega a possibilidade de acordos, de acertos entre as partes antagônicas [...]. Há momentos históricos em que a sobrevivência do todo social, que interessa às classes sociais, lhes coloca a necessidade de se entenderem, o que não significa estarmos vivendo um novo tempo, vazio de classes e conflitos. (FREIRE, 1994, p. 43)

A substantividade democrática na vivência política de que nos fala Freire (1987) requer a prática do diálogo, da busca do entendimento, como princípio que está acima de outros mecanismos e/ou estratégias da luta política de transformação/humanização do mundo. Entretanto, essa posição não pode ser interpretada como dissolução dos interesses de classes diferentes e antagônicas (historicamente situadas em cada sociedade concreta como professam os neoliberais). Há contextos em que o diálogo não é possível e o meio da luta deve ser o enfrentamento de classes, mas, em outros casos, o diálogo também poderá ser a única saída. Obviamente que o diálogo político para a busca de entendimento requer as condições ético-políticas sem as quais não é possível o verdadeiro diálogo. 
É dessa forma que Freire interpreta a luta de classes. Há uma dialética que impulsiona e autorrecria a luta política a partir da qual a mesma assume novos contornos nos diferentes contextos históricos. Nesse sentido, a postura política radical exigida por Freire rejeita toda e qualquer forma de sectarismo nas formas de "ler o mundo" e desenvolver a ação prática de intervenção no mesmo. Tanto o sectarismo de direita (que prega a visão fatalista diante do futuro obrigando-nos a aceitar a realidade tal e qual) quanto o sectarismo de esquerda (que impõe uma visão de domesticação do futuro, ao conceber como necessária a realização de um determinado modelo de sociedade previamente concebido), ambos constituem visões distorcidas e equivocadas do processo político verdadeiramente humanizador da vida em sociedade, pois não mantêm a radical posição democrática diante das exigências de construção solidária e dialógica de uma nova sociedade.

\section{CONSIDERAÇÕES FINAIS}

É imprescindível, então, desencadearmos um verdadeiro processo de reflexão e problematização sobre o mundo, a sociedade e a vida humana constituindo um caminho alternativo da práxis política radicalmente democrática, que de fato reestruture as relações de poder rumo à densidade da cidadania.

Assim, como diz Santos (2007), precisamos lutar cada vez mais na construção de uma democracia de alta intensidade. Esse processo históricocultural requer uma educação progressista enquanto fundamentação da vida social e construção de um sentido existencial para cada ser humano. Educação essa que, respeitando o saber de cada um, que brota do seu Mundo Vivido, oportunize a construção de novos horizontes de vida em sociedade, através de um saber coletivo que dinamize e articule o cotidiano da vida prática com a ciência e a técnica (SANTOS, 1993).

E, nessa perspectiva, um dos grandes desafios da atualidade, diante do ufanismo dos sistemas financeiros e dos mercados globalizados, é a desvirtualização da existência humana hoje fortemente controlada, e até mesmo asfixiada, pelo mundo dos sistemas burocratizantes, que nos desumanizam a todos - ricos e pobres, cultos e analfabetos, velhos e jovens, incluídos e excluídos. Esse processo emancipatório poderá espelhar-se no nosso Mundo da Vida concreto, nas culturas populares e na luta política do povo, que é o grande potencial para reinventarmos as formas da vida democrática, superando as crises que sócio culturalmente nos atingem e desenvolvendo o potencial de humanização intrínseco à própria vocação do ser pessoa. 


\section{REFERÊNCIAS}

DEMO, Pedro. Pobreza Política. São Paulo: Cortez,1993.

FIORI, José luís. O Brasil e seu "entorno estratégico" na primeira década do século XXI. In: FERNANDES, Florestan. A Revolução Burguesa no Brasil: ensaio de interpretação sociológica. 5. ed. São Paulo: Globo, 2006.

FREIRE, Paulo. Pedagogia do Oprimido. 22. ed. São Paulo: Paz e Terra, 1993. . Educação Como Prática da Liberdade. Rio de Janeiro: Paz e Terra, 1967.

Pedagogia da Esperança. 3. ed. Rio de Janeiro: Paz e Terra, 1994.

Pedagogia da Indignação. São Paulo: UNESP, 2000.

FREIRE, Paulo; GUIMARÃES, Sérgio. Aprendendo com a Própria História. Rio de Janeiro: Paz e Terra, 1987.

MEJÍA, Marco R. Transformação social. São Paulo: Cortez, 1994.

SADER, Emir (org.). 10 anos de governos pós-neoliberais no Brasil: Lula e Dilma. São Paulo, SP: Boitempo, 2013.

SANTOS, Boaventura de Sousa. Um discurso sobre as Ciências. Porto: Afrontamento, 1993.

. Renovar a Teoria Crítica e Reinventar a Emancipação Social. São Paulo: Boitempo, 2007. 
Democracia, el poder y la educación popular: reflexiones desde Paulo Freire

Resumen: En el contexto político mundial actual, muchos cambios sociopolíticos están en marcha, y muchos otros que serán capaces de tener éxito. La crisis de la democracia representativa, el regreso de las posiciones conservadoras que abogan por el retorno de la dictadura, el pragmatismo que sólo ve el interés particular, entre muchos otros riesgos para los logros de la democracia brasileña frágil. En esta parte práctica del campo político surgir nuevos retos para las organizaciones de la sociedad civil. Uno de ellos es el debate sobre la reinvención del poder, desde los múltiples espacios sociales, hasta las instancias institucionalizadas del Estado actualmente en vigor, para aprovechar los nuevos logros de vida republicana y no permitir los contratiempos. Freire nos inspira a discutir la naturaleza radical de la democracia y su construcción real de la cultura cívica, que requiere la esperanza para el futuro y la lucha por una sociedad libre y justa como el horizonte de un nuevo proyecto de sociedad.

Palabras-clave: Democracia. Reinventar el poder. La educación popular. Freire. 
Democracy, power and popular education: reflections from Paulo Freire

\begin{abstract}
In the current global political context, many socio-political changes are underway, and many others who will be able to succeed. The crisis of representative democracy, the return of conservative positions that advocate the return of dictatorship, the pragmatism that sees only the particular interest, among many other risks to the achievements of the fragile Brazilian democracy. In this practical part of the political field emerge new challenges to civil society organizations. One is the debate on the reinvention of power, from the multiple social spaces, to the institutionalized instances of the State now in force, to leverage new achievements of republican life and not allow setbacks. Freire inspires us to discuss the radical nature of democracy and its current construction from the civic culture, which requires hope for the future and struggle for a free and just society as the horizon of a new societal project.
\end{abstract}

Keywords: Democracy. Reinventing Power. Popular education. Freire. 